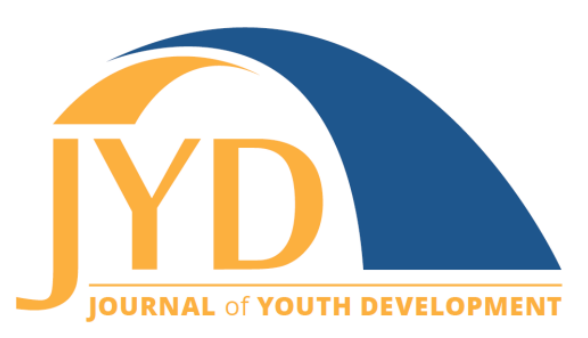

http://jyd. pitt. edu/ | Vol. 14 Issue 4 DOI 10.5195/jyd.2019.839 | ISSN 2325-4017 (online)

\title{
Human-Animal-Environment Interactions as a Context for Child and Adolescent Growth
}

\section{Erin Flynn}

Institute for Human-Animal Connection, Graduate School of Social Work, University of Denver erin.fleming@du.edu

\begin{abstract}
Alexandra G. Zoller
Institute for Human-Animal Connection, Graduate School of Social Work, University of Denver sasha.zoller@du.edu

Megan K. Mueller

Institute for Human-Animal Interaction and Cummings School of Veterinary Medicine at Tufts University megan.mueller@tufts.edu
\end{abstract}

\section{Kevin N. Morris}

Institute for Human-Animal Connection, Graduate School of Social Work, University of Denver kevin.morris@du.edu

\begin{abstract}
Human-animal-environment interaction (HAEI) is increasingly used in special education. While most research of HAEIs has identified effects that broadly support positive special education outcomes, further research of HAEI-based interventions in these environments is needed. Semi-structured interviews were conducted with 18 teaching staff at a special education school that utilizes a range of HAEIs. The teachers are responsible for implementing evidence-based interventions to facilitate social-emotional learning (SEL), so assessing their unique perspectives on the impacts of HAEIs on student SEL outcomes is imperative. Phenomenological coding of the interviews identified 9 major themes that represented positive impacts as well as barriers and challenges experienced by students during HAEIs.
\end{abstract}

Key words: youth development, nature-based interventions, social emotional learning, human-animalenvironment interactions, human-animal bond

(cc) EY New articles in this journal are licensed under a Creative Commons Attribution 4.0 License. This journal is published by the University Library System, University of Pittsburgh and is cosponsored by the University of Pittsburgh Press. The Journal of Youth Development is the official peer-reviewed publication of the National Association of Extension 4-H Agents and the National AfterSchool Association. 


\section{Human-Animal-Environment Interactions}

\section{Human-Animal-Environment Interaction as Context for Growth}

The Individuals with Disabilities Education Act (IDEA) states that research conducted within the special education sector should focus on identifying and developing innovative and effective interventions to promote positive outcomes for children with learning disabilities (U.S. Congress, 1997). Current evidence-based interventions and therapy aimed at contributing to positive results for children with disabilities in schools include applied behavioral analysis, social skills training, and cognitive-behavioral therapy (Adair, Ullenhag, Keen, Granlund, \& Imms, 2015). While these approaches represent progress toward developing evidence-based practices, the outcomes for these students remain inconsistent and the special education sector needs additional interventions, particularly for youth experiencing substantial psychosocial challenges (Cook \& Odom, 2013; Scull \& Winkler, 2011).

A growing body of evidence suggests that human-animal-environment interactions (HAEIs) may provide an additional approach to promoting positive student outcomes when implemented in conjunction with existing interventions. HAEIs combine animal-assisted intervention with nature-based intervention within a positive youth development framework and are conceptualized as mutually influential relationships between humans, non-human-animals, and the broader environment, including nature-based settings. This includes interventions that intentionally use plants, animals, or the natural environment to support human health and wellness; horticultural therapy; gardening; activities in nature (e.g., hiking); and conservation activities that are focused on improving human well-being, mental health, learning or physical impairments, and environmental health (Moeller, King, Burr, Gibbs, \& Gomersall, 2018). In general, intentional exposure to nature has been found to bolster positive effects for specific diagnoses, including dementia (de Bruin et al., 2015) and clinical depression (Gonzalez, Hartig, Patil, Martinsen, \& Kirkevold, 2011). HAEIs have also been shown to provide additional benefits, such as higher levels of concentration after participation (Bowler, Buyung-Ali, Knight, \& Pullin, 2010).

Research conducted on specific types of HAEIs suggest that these interventions support student outcomes in special education settings. For example, horticultural interventions improved several target areas for students, including social abilities, cooperation with peers, self-assertion in social situations, students taking responsibility for their actions, and self-control (Kim, Park, Song, \& Son, 2012). Similarly, animal-assisted interventions have been found to address a wide range of psychosocial issues in youth in special education, such as interventions that involved dogs, horses, and guinea pigs to reduce autism-spectrum symptoms (O'Haire, 2013; O'Haire, 


\section{Human-Animal-Environment Interactions}

McKenzie, McCune, \& Slaughter, 2014). A 12-week canine-assisted, cognitive-behavioral therapy program was found to reduce classroom behavioral issues in students with ADHD (Schuck, Emmerson, Fine, \& Lakes, 2013). An 11-week randomized trial of an equine-assisted education program promoted social competence (Pendry, Carr, Smith, \& Roeter, 2014) and a meta-analysis of 49 studies found moderate effect sizes in a number of areas including emotional well-being and developmental delays (Nimer \& Lundahl, 2007). Additionally, HAEIs have been shown to improve intellectual and social outcomes in youth including their capacity for directed attention, increased problem solving, communication, school success, engagement, and behavioral management (Annerstedt \& Währborg, 2011). Another study found that children who engaged in nature-based activities in school settings were off task less frequently and required less redirection by their teacher, and teachers reported an increase in their students' overall well-being (Largo-Wight et al., 2018).

A variety of HAEIs are increasingly used by education professionals to supplement established interventions to enhance the health and well-being of students experiencing a range of clinical and social needs in special education (Moeller et al., 2018). However, further research is needed to optimize how HAEIs might be developed and implemented as additional evidencebased support for youth in special education. Much of the existing research focuses on outcomes assessment, which, while useful, does not elucidate the specific features of HAEIs that can lead to youth development outcomes. Particularly for youth in special education settings who may have a diverse range of educational challenges, there is a need to identify what features of HAEIs may be useful for targeting specific skills. Understanding the processes by which HAEIs function within special education environments will help educators and practitioners design specific activities to meet student goals.

Special education teachers are uniquely situated to assess how students may experience, and be impacted by, different interventions. They hold important perspectives of how HAEIs may affect student SEL outcomes because they hold expertise in student assessment, learning dynamics, and spend substantial time working closely with students daily and over the course of a year (Granger \& Kogan, 2006). Teachers work with individual students to strengthen conflict resolution and other interpersonal skills, develop better behavior and emotion management, and support their overall wellbeing and academic outcomes (Gable, Tonelson, Sheth, Wilson, \& Park, 2012). They observe first-hand how students behave in different settings, such as the classroom, non-academic areas on a campus and the natural settings used in HAEIs (Granger \& Kogan, 2006). Therefore, their comparative views fill a gap in what is currently known about the SEL outcomes of HAEIs in special education settings, which are largely informed by self- 


\section{Human-Animal-Environment Interactions}

report measures. Filling this gap will help researchers identify the potential effects youth in special education experience while in more nature-rich environments.

\section{Method}

\section{Qualitative Approach}

This study used a phenomenological approach to understand the perspectives of special education teachers regarding how HAEIs impact the social skills, behavior management, and wellbeing of youth. Specifically, this study addressed the following research questions from the perspective of teachers:

1. Are student SEL outcomes impacted by participation in HAEIs?

2. If so, how are impacts of HAEIs on student SEL outcomes achieved and are they sustained and/or generalized to other contexts?

3. What are the potential challenges or barriers to implementation of HAEIs as interventions that benefit special education students' social-emotional growth?

The phenomenological approach was well-suited to addressing these research questions because of its emphasis on identifying common meanings that underlie individuals' lived experiences or, in other words, the subjective and objective knowledge individuals gain from their experiences in daily life (Creswell \& Poth, 2018). Key to this approach is the suspension of researchers' assumptions about what is real. This yields information that has a high level of validity that can inform directions of further inquiry and implications for practice (Streubert \& Carpenter, 1999). This study focused on describing the essence and nature of special education teachers' lived experiences of using HAEIs as a tool to improve youth SEL outcomes and to promote positive trajectories of development.

\section{Participants}

All participants were recruited in collaboration with Green Chimneys' executive staff using emails and direct outreach from the research team that detailed the purpose of the study. Interested teaching staff met with researchers on the school's campus. Each participant received $\$ 10$ as an incentive to participate. The target sample size $(n=18)$ was chosen based on standard sample sizes for phenomenological studies (Creswell \& Poth, 2018) and to allow for inclusion of both special education teachers $(n=7)$ and teaching assistants $(n=11)$ and still reach saturation. 


\section{Human-Animal-Environment Interactions}

Semi-structured interviews were conducted at Green Chimneys, an approved New York State private school for special education and psychological treatment. The Green Chimneys campus includes an array of HAEIs, including equine programs, farm animals, wildlife, dog training, gardening and outdoor programs that are often referred to collectively as "the farm." There are over 300 domesticated farm and wildlife animals that live on the Green Chimneys campus (Green Chimneys holds a Class C license from the U.S. Department of Food and Agriculture). Children learn to interact with animals in a wide variety of contexts on the campus and participate in providing the animals with daily care. Animals are incorporated into the educational and treatment milieu at Green Chimneys to enhance experiential learning for students. This includes attending classes (each 37 minutes) in the farm animal, equine, wildlife, and garden program areas as part of their weekly class schedules. These classes focus on topics that draw from the required core curriculum and integrate HAEIs. Separately, protocols are in place for teaching and behavior support staff to make nature, gardens, and animals available to students on an as-needed basis when they have difficulty in the classroom and need a break.

Inclusion criteria required that the individual be employed by Green Chimneys as a special education teacher or teaching assistant, and work with children between the ages of 6 and 19 years with emotional disturbances, learning disabilities, and/or other mental health impairments. On average, the participants taught children who were 10 years of age ( $S D=5.0$, range: 6 to 19). Seven participants identified as male and 11 as female. Fourteen individuals identified as White, 3 as Black, and 1 as Black/Caribbean. Seven participants were teachers and 11 were teaching assistants; they taught varying subjects and grade levels. The participants had a range of 1 to 39 years of teaching experience on site.

\section{Data Collection Procedures}

Before the interview researchers discussed the process with the staff member according to the University of Denver IRB-approved recruitment script, and each participant was given the opportunity to ask questions about the study before signing the consent form. Participants answered a brief demographic survey and then completed a 30-minute interview, which was conducted either in the participant's office or another private workspace to encourage participants to speak openly. The interviews began with the broad, open-ended question: "How have you seen kids be impacted by the farm and nature-based interventions here?" which used language commonly used by staff members to refer to HAEIs. This initial question made the 


\section{Human-Animal-Environment Interactions}

assumption that HAEIs had some degree of impact on students and used follow-up prompts to explore the possibility that HAEIs had no impact on students (see below).

To collect as much narrative data as possible, interviewees were asked their views on the immediate and long-term outcomes of student participation in HAEIs and further prompted with open-ended questions including:

1. Have you seen instances when students weren't impacted by farm or nature-based programs or were negatively impacted?

2. Have you seen students benefit from farm or nature-based programs?

3. Did you notice students learning anything specific from the farm and nature-based programs?

To reduce researcher bias, researchers worded prompts to be open-ended, avoided leading questions, and asked about positive, negative, and no impacts. This allowed for greater range, depth, and nuance to arise from subsequent analysis of staff perspectives and encouraged participants to speak about features of students' outcomes that they believe to be most salient. Interviews were audio recorded and stored on password-protected devices and later transcribed by one graduate research assistant according to a standard protocol. To ensure accuracy, a second researcher read through the transcript while listening to the recorded interview and made corrections when there was a discrepancy between the transcript and recording. Additional steps to reduce researcher bias included use of verbatim transcriptions of interviews and use of in vivo coding during initial analysis.

\section{Data Analysis}

Transcripts were examined by the entire research team for broad themes using a phenomenological approach to identify each interviewee's unique, lived experience and understanding of the phenomenon (Banonis, 1989). Researchers utilized a seven-step process of data analysis to develop a detailed understanding of teachers' interpretation of the effects of HAEIs on youth (Diekelmann et al., 1989):

1. Read each transcript.

2. Glean an overall meaning.

3. Identify themes.

4. Memo interpretive summaries of themes that arose.

5. Code the content from the identified themes that emerged from the initial memoing process. 


\section{Human-Animal-Environment Interactions}

6. Review the identified themes for their common meanings.

7. Group themes together via identified constitutive content that linked the themes to one another.

This process allowed for rigorous and consistent interpretation and analysis of the data according to best practices in phenomenological methods (Diekelmann, Allen, \& Tanner, 1989). The grouped themes were reviewed by the research team for codes that did not pertain to the research question, which were removed, or those that needed to be combined further.

\section{Credibility and Trustworthiness}

To test validity, themes developed from coding of the interviews were shared with the research participants who were asked to give feedback on accuracy (Diekelmann et al., 1989). The researchers emailed a summary of the findings to the participants and asked them to confirm, add or change any of the themes (Guba \& Lincoln, 1989). Of the 18 participants, only two (1\% response rate) participated in respondent validation. This was partly due to the high rate of staff turnover at the time of the study, as six participants had left the school. Ten participants were still employed by the school but did not respond, which may have been related to the lack of additional incentives, the length of time between interview and respondent validation, and already high workloads of teaching staff. Staff who participated in the validation process reported that the findings were concurrent with their original thoughts and did not offer changes or suggestions.

\section{Results}

The data analysis produced 71 individual codes that were grouped into nine major themes, with some sub-themes, regarding how teaching staff view the impacts of HAEIs on youth involved in special education (Figure 1). These findings detailed perceptions of both short-and long-term impacts of HAEI interventions and included views that these interventions have barriers and challenges to implementation, as well as substantial and profound effects on the educational, behavioral, and clinical aspects of youths' experiences. Teachers noted improvements in students' overall behavior, competence, confidence, connection with others, levels of curiosity, interest and excitement about subjects, mood regulation, overall motivation, and having an expanded worldview. 
Figure 1. Nine Major Themes With Subthemes That Arose From the Data Analysis

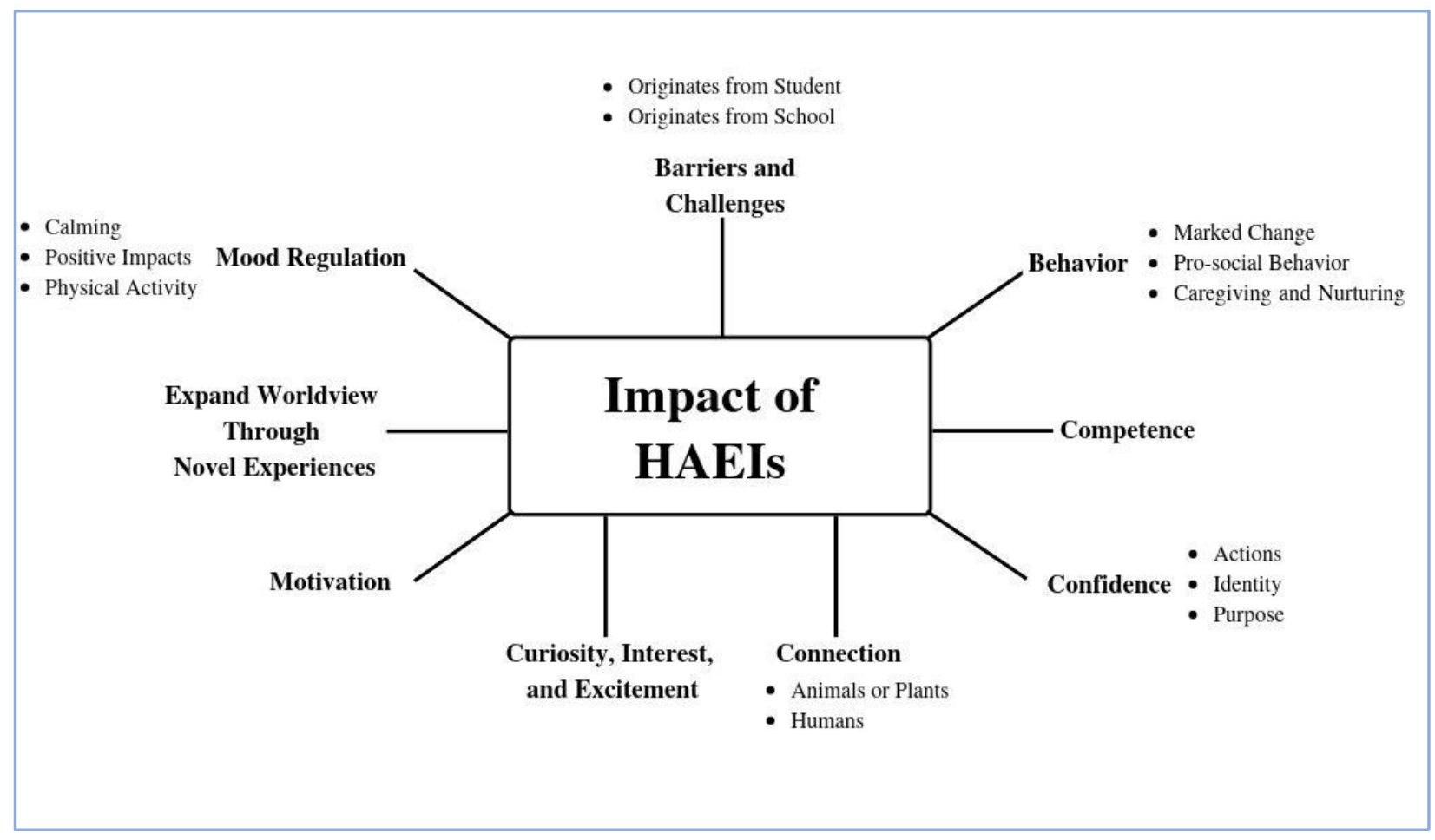

\section{Theme: Barriers and Challenges to Implementing HAEIs}

Barriers and challenges, which sometimes interfered with the positive impacts of HAEIs, were a primary theme reported. These fell into two categories: barriers and challenges due to the school's environment and those that stemmed from the students themselves. Barriers related to the school environment were comprised of program structure (e.g., schedule changes and staff availability), inclement weather, and disruptions that impacted the student's ability to engage in the programs (e.g., disruptions in the dorms at night causing a student to be tired the next day and having greater difficulty staying regulated).

The most impactful barriers and challenges that emerged from the coded interviews were those that originated from the students themselves, including: students' allergies to an animal or plant, fear of an animal or a plant, lack of interest in the nature-based activity, having a sensory issue that interfered with their involvement, unsafe behaviors, difficulty sharing an animal or plant, and not wanting a close relationship with a plant or animal. One teacher stated that she thought that

[Students who had experienced trauma] just don't want to be close with anything. And they feel as if having an animal next to 
Human-Animal-Environment Interactions

them [is] closeness and they don't want that bond or relationship.

So, I think at a young age that child realized that, "I need to push

anything that gets close to me away."

A unanimous theme from the teacher interviews was that these barriers and challenges occurred infrequently, and many students were able to eventually overcome barriers related to fears and sensory issues that had previously stopped them from participating in animal, plant, and nature-based activities.

\section{Theme: Impacts of HAEIs on Behavior}

Another theme that emerged was that of changes in students' behavior and three sub-themes related to specific changes that occurred in the classroom and students' daily interactions after engaging in HAEIs. These included marked improvements in behavior regulation while in proximity with animals, plants, or nature; nurturing or caregiving actions toward animals or plants; and engaging in prosocial tactics with peers, teachers, and farm workers. A common observation was that while students were in the presence of animals or plants there was often a complete change in their behavior regulation; this was seen even to the point where they were viewed as acting like "a completely different person."

One math teacher noted that their student, after learning to groom and ride horses had "a lot of changes [in the classroom]. He's much more mature now and he doesn't yell anymore. Sometimes he still taps certain things and he does math like this, in the air. But he's entirely different now." This change in behavior was also evident outside of the classroom when students worked on the farm. One teacher reported, "A lot of our students, they come in very rigid, very set on very concrete things. But working with animals and working on the farm, you can see that [they are] much more relaxed, able to kind of go with the flow a little bit more." Classrooms as a whole are also impacted by exposure to HAEI contexts, with teachers reporting that students overall had improved behavior regulation. A kindergarten teacher described that when a dog came into the classroom her students,

Don't talk so loud[ly]. Whispering voices for 45 minutes.

Hyperactive kids will bounce off the wall [and we'll b]e like,

"There's a dog right here. He needs you to calm down so he can come to you." Then they'll sit there for 45 minutes just so they can play with the dog. It's like, I try this all day for hours, and nothing, but you put them around the animals, they're completely different people. 


\section{Human-Animal-Environment Interactions}

Teachers noticed that when students were around animals or plants, their behavior became more caregiving and nurturing towards the animals or plants. Teachers did not typically see these behaviors in their students' interactions with peers or adults. One teacher described how a student recognized, "these animals are nonverbal, but they need care too. So, they have to be gentle and they have to be caring to the animals and that they are able to provide unconditional love."

Additionally, teachers shared that during and after HAEIs students engaged in prosocial behaviors with other students and among adults and behaviors seeking social acceptance and friendship. These behaviors included awareness of the needs of others and showing greater tolerance of the challenges presented by the animals. For example, one teacher reported, "I think they're more apt to accept mistakes as a mistake and kind of move on with an animal. I guess there's a distinction there where it's like it's all right for this animal to make mistakes and it's okay and we can move past it."

Another prosocial behavior that students exhibited was their ability to follow the rules more easily and have greater awareness of their actions. One teacher reflected that student interactions with the dogs in the classroom prompted them to follow the rules by "being calm, being patient, being nice, being gentle, watching their tone of voice, watching how loud they are, watching their physical mannerisms, their proximity to the animals. 'How close am I?', 'Is this going to make the dog uncomfortable?"' This awareness of actions extended to their peers as students started to teach and hold their peers accountable to the rules when interacting during HAEIs. One teacher reported,

With new people that come in, they tell them the rules. You literally step back, and you let the kids train the new ones. They're like, "This is what we're going to do. You can't do this or else we won't be able to come back with the animals." They train each other.

These changes in students' approach to interpersonal relationships are also seen in students' encouragement and support of each other while interacting with animals and plants. One kindergarten teacher remembered how their students realized:

[They] all have problems, so you can't make fun of someone for being scared of an animal. They're not laughing at each other; they're not making fun of each other. They stick up for each other. They're like, "If he's scared, then he's scared. Just don't put 
Human-Animal-Environment Interactions

it around him." They literally take that, "Okay, he's scared so we'll

just go to the opposite side of the table, just so he doesn't touch

it." They really look out for each other when it comes to the

animals.

\section{Theme: Impacts of HAEIs on Competence}

Another theme was that of students displaying greater competence, including acting responsibly, and generalizing new skills across different contexts. One teacher shared, I can see that [they practice] the same interaction [from when] the dogs come into the classroom. You know, this one kid in particular, if he sees a kid is having a hard time, will go up and give the kid a hug and say, "It's okay."

Several teachers noted that this competence included students' ability to overcome their fears. [Students] who were afraid of the horses at first . . . they go to the riding class and they master it and they want to because they learn it's not gonna hurt you, you can do it, and it's something they master, which is so beneficial to anybody.

Mastery of skills was also noted as a common student experience as they gained expertise in certain topics related to plants and animals. Teachers reported that their students often became extremely knowledgeable about a certain animal:

They're just very knowledgeable, I noticed. Even just in regular conversation, they'll tell me about the lifespan of [different animals] . . . one of our kids, he knows all about ducks. He loves ducks... he's like, "did you know that the Pekin duck is one of the domesticated ducks?" I'm just sitting here like, "yeah, okay." But then I did the project with him and he was actually . . . all of the facts that he was telling are true. So they definitely take that with them, it sticks.

\section{Theme: Impacts of HAEIs on Confidence}

After HAEIs, students exhibited increased confidence in their identity, purpose, and actions. Regarding identity, teachers noted that students began to feel that it was okay to be themselves. The students had bolstered self-worth, self-esteem, and overall confidence. For 


\section{Human-Animal-Environment Interactions}

example, one English teacher reflected that students "get to experience pride [and] a boost in self-esteem because they feel that they are giving something positive back to the animals." Another teacher spoke about the link between students caring for another living thing and their own sense of accomplishment. She described students' time spent working in the garden,

They're actually caring for something living . . they love to see their work grow. I know one of the girls ... she picked the biggest tomato and they served it at lunch. She was really proud of herself . . . I think it's about the work aspect of the garden, it really does make them feel proud.

Teachers also reported that HAEIs helped students clarify their views on their purpose in life. For example, students felt needed and that their actions were purposeful when interacting with plants and animals. Students' work with plants and animals gave them a "sense of accomplishment" and made them "realize that this is something they do that makes a difference" and their actions made "them feel like [they were] giving back."

\section{Theme: Impacts of HAEIs on Connection}

Overall, teachers felt that students had meaningful relationships and bonds with plants and animals and that these strong connections facilitated relationships with other people. Teachers viewed this as being due to several factors, including that animals and plants are not perceived to have ulterior motives and interactions with them provide tangible connection. One teacher noted,

These kids want to give, but it's hard when you don't trust humans anymore. You don't know what's around the corner in the classroom, but you know that that animal is steadfast and that it's always going to be [a] cow. It's always going to like a treat, or the sheep are always going to be the same.

This theme of continuity of relationships was also found when teachers reported that animals and plants provide students with a "feeling of safety" that helped them form close relationships more easily. Students recognized the likeness between themselves and the animals or plants. A middle school teacher noticed,

A lot of the dogs, even personality-wise, some of the kids like to gravitate to animals who they feel have the same personality traits they [have] whether they're quirky, whether they're snooty, 
Human-Animal-Environment Interactions

whether they are super friendly or shy. I think a lot of the kids can find an animal here who displays the same traits and then they can kind of find a friend in that and say, "Hey, this is acceptable. People love this animal regardless of them being shy." Some of the llamas are shy. "Hey, it's all right. Everybody loves this llama, so everybody could love me too even though I'm shy." I think they definitely make . . . a lot of the kids make those connections. "Hey, one of the horses ran out of the horse barn and they had to go catch them. Oh, that was like me the other day but you know what? He did the right thing. He came back and everything was fine. "So, I definitely think they can make those connections which is awesome.

Teachers believed that it is due to the relationships their students had with plants and animals that they were able to have deeper relationships with other people including teachers, staff, clinicians, and their peers. Often the strongest relationships students formed with other people were with the staff who worked in close proximity with animals. One teacher mused,

They have relationships with these animals and . . the ability to have a relationship with another living thing, then they can all of a sudden look at their peers and their staff and say okay, you're not going to hurt me and you're not going to betray me. Maybe I can have a relationship with you too.

\section{Theme: Impacts of HAEIs on Curiosity, Interest, and Excitement}

Students' interactions with animals and plants cultivated curiosity, interest, and excitement about things outside of themselves. This theme was illustrated by teachers' descriptions of students asking questions about certain animals or plants, expressing excitement to engage in the HAEIs, or becoming inquisitive about the animals or plants, rather than focusing on themselves.

He'll just stand over at the gate of either the dogs, or the cows in particular, and just stare at them and say "hey, do you see how she's sleeping, she's sleeping right now, "and then they start asking the questions of weather and food, "do they have water, why are they making sounds like that? Why is it named this? Where did it come from?" So a lot of who, what, when where, 


\section{Human-Animal-Environment Interactions}

why start to come up and then they're able to reflect it back on them[selves].

\section{Theme: Impact of HAEIs on Mood Regulation}

Plants and animals were thought to have a profound, positive impact on students' moods. For example, teachers described how plants and animals elicited happiness and joy, gave students a physical outlet that promoted positive affect, and calmed students. The presence of these interventions, even brief interactions of 5 to 10 minutes, helped kids return to baseline (i.e., a well-regulated state) and were sought out in times of distress. One teacher explained, "The horse had brought him back to baseline. He'll go on the horse and come off and say, 'you know, that really brought me back to where I need to be."' This effect was also seen with plants, as a teacher described:

[They were] more relaxed, you can see them understand that I'm in a better place now, I'm where I like to be and where I want to be in terms of just feeling that tranquility and peace and being able to feel the ease of not feeling the anger again, and forgetting at the end, "What the heck was I mad at before?"

and,

$$
\begin{aligned}
& \text { A lot of [students] ask me at times, "Can I help at the garden?" } \\
& \text { Or, "Can I work there so that I can actually relieve some stress } \\
& \text { and some anger that I have? Like I got to do some shoveling, } \\
& \text { planting. "Anything of that sort, just to let that out. }
\end{aligned}
$$

\section{Theme: Impacts of HAEIs on Motivation}

Another theme that emerged was that animals and plants motivated students to follow classroom rules, work with their peers, and persevere through situations that can be unpleasant in order to have opportunities to interact with animals and plants. Sometimes the motivation was general, as one teacher described of the garden, "They loved it. And a kid would never eat a radish. But I think them growing it themselves changes it." Motivation was also explained by a kindergarten teacher who saw her students "sit quietly . . . let [the dog] come to them, they share, they participate. They do what they can so they can play with the animal." Another teacher remarked that her students worked better together when an animal was present; students "share, they communicate, they speak to each other. They are like, 'oh, you want to 


\section{Human-Animal-Environment Interactions}

feed it too? Okay, I can share with you.' But you hate to share. Where is this coming from? You've never done this."

\section{Theme: Worldview Expanded Through Novel Experiences}

One of the most powerful interactions teachers noticed was when students who had little access to nature or animals came into contact with a wide variety of nature for the first time. Through this, they saw that youth were able to experience new things, expand their world view and better understand how they fit into the world. One teacher reflected,

We have kids that come from the city or kids that come from someplace who have never been to a farm. They've never had the experience of seeing farm animals. So those children, to watch their reactions, of "we're going and we're gonna go collect chicken eggs." "Really?" [I]t is amazing.

Another teacher described a time when she and her class took charge of a garden in front of the school building.

We turned it into a butterfly and hummingbird garden...A lot of [the students] would spend all of recess time weeding instead of out playing and then they were so thrilled when a butterfly started coming and we'd see the hummingbirds from class and they really got into it. They especially enjoyed it when other staff and students would stop to admire the flowers or the butterflies.

\section{Discussion}

In this study, the perspectives of special education teaching staff were examined to ascertain the impacts that HAEIs had on students. The teachers' unique perceptions of these outcomes were extracted from interview transcripts and analyzed to understand this phenomenon. Nine major themes emerged from the analysis of coded transcripts, which included: barriers and challenges faced by the students when they interact with HAEIs; impacts on students' behavior; competence; confidence; connection; curiosity, interest, and excitement; mood regulation; motivation; and novel experiences.

The most prevalent perception of positive impacts of HAEIs on youth in this special education setting included students fostering connection with others, changing their behavior, and 


\section{Human-Animal-Environment Interactions}

facilitation of students' self-regulation. Teacher reflections on these impacts elucidated some of the processes involved in HAEIs, such as relationship building with both animals and people, animals supporting motivation and communication, and opportunities for self-reflection. In contrast, the barriers and challenges that were mentioned the most by teachers were students' unsafe behaviors that could harm an animal, plant, or person; their lack of interest in a HAEI; and fear of an animal or plant.

These findings were consistent with existing research that found that HAEIs had a general positive impact on participants (Bowler et al., 2010). More specifically, HAEIs were shown to have a positive impact on special-education students' social abilities (Kim et al., 2012), autismspectrum symptoms, emotional well-being, and reduced behavioral issues and developmental delays in youth who were in need of special education support (Hoagwood, Acri, Morrissey, \& Peth-Pierce, 2017; Jones, Rice, \& Cotton, 2019; Nimer \& Lundahl, 2007; O'Haire, 2013). However, previous studies of HAEIs on special education students examined narrow facets of HAEIs, such as specific horticultural or animal-assisted interventions. Further, teacher perceptions to understand potential impacts of HAEIs are rarely utilized. In contrast, the present study examined the full range of HAEIs incorporated into Green Chimneys, including horticultural-, animal-, and natural environment-based, and their possible impacts on students in special education. Thus, this phenomenological study provides additional context around how exposure to a broad range of HAEIs may support social skills, behavioral management, and well-being, specifically among children in special education with individualized education plans.

\section{Directions for Future Research and Implications for Practice}

The themes found in this study represent a wide range of target areas that students in special education who participate in HAEIs may benefit from, such as improved social skills, motivation to engage in activities, increased regulation, and greater connection. These benefits may foster student success in the academic settings and should be explored as a potential complementary intervention in special educational settings.

Several barriers were also identified with regard to both individual student and school context factors that potentially impede the effectiveness of HAEIs. Better understanding of these factors can help schools, teachers, and practitioners design and implement HAEIs more successfully for different students. For example, there may be a need for more robust protocols around how to manage student behavior that is unsafe to scaffold their experience in a way that allows them to re-engage with the HAEI as they are able. Fear and uncertainty in working with animals was 


\section{Human-Animal-Environment Interactions}

noted as a potential barrier to participation, and for these students, it may be beneficial to engage clinical staff to work on an individual plan to facilitate working through the specific fear. Lack of interest in students, while not particularly common, is an important reminder that not all students will choose to participate in HAEIs, underscoring the need for appropriate screening procedures for these interventions to ensure fit with an individual child's needs.

Overall, more research is needed to understand the impact of HAEIs on short- and long-term student outcomes, including use of mixed methods study designs that quantify the impacts and isolate the mechanisms of change. Studies also need to account for the student diversity (e.g., racial/ethnic, diagnoses) in special education. Additionally, research is needed that solicits the point of view of students themselves and of other key figures in students' lives including guardians, therapists, and residential staff. These diverse perspectives will yield a more comprehensive picture of the impacts of HAEIs on students that represents varying domains in students' daily lives.

Although this study provides valuable insight, it had several limitations. First, it was limited to teachers' perceptions of the impact that HAEIs had on their students. When sharing their perceptions, the teaching staff may not have taken into account confounding factors that could account for the positive impacts they saw students experience, such as therapy, skill building, maturation over time, or external life factors that occurred outside of the context of a HAEI. Second, the study took place at a special education school that is world-renowned for its incorporation of a broad array of HAEIs into their practices. This setting may have biased the teaching staffs' perception towards the positive impacts of HAEIs on students, as opposed to recognizing the possible negative impacts. Third, the participants were mostly white females and the findings may not be generalizable to more diverse groups. Finally, it is unknown to what degree teaching staff considered the impacts that HAEIs might have on students prior to this study; lack of prior abstract thinking about the impacts of HAEIs or metacognition about possible biases may have diluted the scope of responses from the teaching staff. In spite of these limitations, this study offers important insights from the perspectives of teaching staff regarding HAEIs' impacts on students in special education settings. As HAEIs gain popularity as an intervention for youth in special education it is necessary to further examine the effects of these types of interventions and how schools can utilize HAEIs in an ethical way to promote students' well-being and growth. 


\section{Human-Animal-Environment Interactions}

\section{Acknowledgements}

Funding for the study was provided through a grant from the Green Chimneys Board of Directors for research aimed at measuring the impacts of the Green Chimneys HAEI program on student outcomes. The grant contract includes a statement that the principal investigator has full authority to publish both positive and negative findings with regard to the impacts of these programs.

We thank all participating Green Chimneys teachers and staff.

\section{References}

Adair, B., Ullenhag, A., Keen, D., Granlund, M., \& Imms, C. (2015). The effect of interventions aimed at improving participation outcomes for children with disabilities: A systematic review. Developmental Medicine \& Child Neurology, 57(12), 1093-1104. doi:10.1111/dmcn.12809

Annerstedt, M., \& Währborg, P. (2011). Nature-assisted therapy: Systematic review of controlled and observational studies. Scandinavian Journal of Public Health, 39(4), 371-388. doi:10.1177/1403494810396400

Banonis, B. C. (1989). The lived experience of recovering from addiction: A phenomenological study. Nursing Science Quarterly, 2(1), 37-43. doi:10.1177/089431848900200111

Bowler, D. E., Buyung-Ali, L. M., Knight, T. M., \& Pullin, A. S. (2010). A systematic review of evidence for the added benefits to health of exposure to natural environments. BMC Public Health, 10(1), 456. doi:10.1186/1471245810456

Cook, B. G., \& Odom, S. L. (2013). Evidence-based practices and implementation science in special education. Exceptional Children, 79(2), 135-144. doi:10.1177/001440291307900201

Creswell, J. W., \& Poth, C. N. (2018). Qualitative inquiry \& research design: Choosing among five approaches. Thousand Oaks, California: Sage.

de Bruin, S. R., Stoop, A., Molema, C. C., Vaandrager, L., Hop, P. J., \& Baan, C. A. (2015). Green care farms: An innovative type of adult day service to stimulate social participation of people with dementia. Gerontology and Geriatric Medicine, 1. doi:10.1177/2333721415607833

Diekelmann N., Allen D., \& Tanner C. (1989). The NLN criteria for appraisal of baccalaureate programs: $A$ critical hermeneutic analysis. New York, NY: NLN Press.

Gable, R. A., Tonelson, S. W., Sheth, M., Wilson, C., \& Park, K. L. (2012). Importance, usage, and preparedness to implement evidence-based practices for students with emotional disabilities: $A$ comparison of knowledge and skills of special education and general education teachers. Education and Treatment of Children, 35(4), 499-520. doi:10.1353/etc.2012.0030 


\section{Human-Animal-Environment Interactions}

Gonzalez, M. T., Hartig, T., Patil, G. G., Martinsen, E. W., \& Kirkevold, M. (2011). A prospective study of existential issues in therapeutic horticulture for clinical depression. Issues in Mental Health Nursing, 32(1), 73-81. doi:10.3109/01612840.2010.528168

Granger, B. P., \& Kogan, L. (2006). Animal-assisted therapy in specialized settings. In A. H. Fine (Ed.) Handbook on animal-assisted therapy: Foundations and guidelines for animal-assisted interventions (pp. 213-236). San Diego, CA: Academic Press.

Guba, E. G., \& Lincoln, Y. S. (1989). Fourth generation evaluation. Newbury Park, CA: SAGE. Hoagwood, K. E., Acri, M., Morrissey, M., \& Peth-Pierce, R. (2017). Animal-assisted therapies for youth with or at risk for mental health problems: A systematic review. Applied Developmental Science, 21(1), 1-13. doi:10.1080/10888691.2015.1134267

Jones, M. G., Rice, S. M., \& Cotton, S. M. (2019). Incorporating animal-assisted therapy in mental health treatments for adolescents: A systematic review of canine assisted psychotherapy. PloS One, 14(1), e0210761. doi:10.1371/journal.pone.0210761

Kim, B. Y., Park, S. A., Song, J. E., \& Son, K. C. (2012). Horticultural therapy program for the improvement of attention and sociality in children with intellectual disabilities. HortTechnology, 22(3), 320-324. doi:10.21273/HORTTECH.22.3.320

Largo-Wight, E., Guardino, C., Wludyka, P. S., Hall, K. W., Wight, J. T., \& Merten, J. W. (2018). Nature contact at school: The impact of an outdoor classroom on children's well-being. International Journal of Environmental Health Research, 28(6), 653-666. doi:10.1080/09603123.2018.1502415

Moeller, C., King, N., Burr, V., Gibbs, G. R., \& Gomersall, T. (2018). Nature-based interventions in institutional and organisational settings: A scoping review. International Journal of Environmental Health Research, 28(3), 293-305. doi:10.1080/09603123.2018.1468425

Nimer, J., \& Lundahl, B. (2007). Animal-assisted therapy: A meta-analysis. Anthrozoös, 20(3), 225-238. doi:10.2752/089279307X224773

O'Haire, M. E. (2013). Animal-assisted intervention for autism spectrum disorder: A systematic literature review. Journal of Autism and Developmental Disorders, 43(7), 1606-1622. doi:10.1007/s10803012-1707-5

O'Haire, M. E., McKenzie, S. J., McCune, S., \& Slaughter, V. (2014). Effects of classroom animal-assisted activities on social functioning in children with autism spectrum disorder. The Journal of Alternative and Complementary Medicine, 20(3), 162-168. doi:10.1089/acm.2013.0165

Pendry, P., Carr, A. M., Smith, A. N., \& Roeter, S. M. (2014). Improving adolescent social competence and behavior: A randomized trial of an 11-week equine facilitated learning prevention program. The Journal of Primary Prevention, 35(4), 281-293. doi:10.1007/s10935-014-0350-7

Schuck, S. E., Emmerson, N. A., Fine, A. H., \& Lakes, K. D. (2013). Canine-assisted therapy for children with ADHD: Preliminary findings from the Positive Assertive Cooperative Kids study. Journal of Attention Disorders, 19(2), 125-137. doi:10.1177/1087054713502080 
Journal of Youth Development | http://jyd.pitt.edu/ | Vol. 14 Issue 4 DOI 10.5195/jyd.2019.839

Human-Animal-Environment Interactions

Scull, J., \& Winkler, A. M. (2011). Shifting Trends in Special Education. Thomas B. Fordham Institute. Retrieved from https://eric.ed.gov/?id=ED520416

Streubert, H. J., \& Carpenter, D. R. (1999). Qualitative research in nursing: Advancing the humanistic imperative. Philadelphia, PA: Lippincott Williams \& Wilkins.

U.S. Congress. Senate Committee on Labor and Human Resources. (1997). Individuals with disabilities education act amendments of 1997: report (to accompany S. 717). Washington, DC: U.S. G.P.O. Retrieved from https://babel.hathitrust.org/cgi/pt?id=pur1.32754067410765 